\title{
10
}

\section{Vortices and Fish Schools}

\author{
C. M. BREDER, JR. \\ The American Museum of Natural History
}

(Plates I-IV; Text-figures 1-3)

\section{INTRODUCTION}

$\mathrm{T}$ HE recent increase in research on the formation and organization of fish schools, especially that bearing on the ecology and development of such assemblages, has produced some distinctly useful information. See, for instance, E. Shaw (1958a and b, 1961), Cahn \& Shaw (1963 and MS.), John (1964). None of these investigators, however, has explored the hydrodynamic aspects and consequences of the effects of the passage of solid bodies such as fishes through fluid media, although all are apparently aware of the problem. The published results of current researches in the fields of hydrodynamics, fluid mechanics and hydraulics form a considerable literature, some of which is distinctly pertinent to problems of fish locomotion and social grouping, including such studies as Rosen (1959), W. Shaw (1959), Birkhoff (1962), Rouse (1946 and 1963) and Gadd (1963a and b). Rosen and Gadd cover the application of modern fluid mechanics to studies on fish locomotion, which is, of course, especially germane to schooling problems.

Since swimming fishes envelop themselves in a series of vortices and leave a dying trail of them behind, it follows that these features of fluid mechanics become a factor in the environment of other fishes which approach or follow. The broader aspects of the hydrodynamic details of the environment within which fish schools operate are discussed herein. Other types of social assemblages of fishes are not discussed in detail at this time for reasons which will be indicated later. The usage of "aggregations," "school," "pods" and related terms follows that of Breder (1959).

The phenomenon of continuing vortex formation by the relative motion between a mass of fluid and a solid object immersed therein was first discussed in detail by Kármán (1912). These series of vortices, which stream after such an object, are usually referred to as Kármán vortex sheets, trails or streets. However, it has only been in recent years that investigators have begun to consider their possible importance to studies of fish locomotion. Two possible approaches will be considered. The first is that of the interaction and consequences of the vortices cast off by each fish. In this, the fishes' reactions to other naturally-occurring vortices are also examined. The second is that in which an entire school of fishes is itself considered a vortex when it forms a closed figure. Such closed figures, usually almost circular, rotate as a whole but have no forward translation. The individual fishes face and circulate all clockwise or all counterclockwise. Such groups are usually called fish mills.

Appreciation is acknowledged for assistance from the following: to Miss Sara L. Page, a Lincoln Ellsworth field assistant, for laboratory and field assistance in the experimental work; to Mrs. Mary G. Hume, Scientific Assistant of the Department of Ichthyology, for laboratory and office assistance; to the Goodyear Aircraft Corporation for permission to use certain films for study and the photographs in Plate I; to $\mathrm{Mr}$. George A. Bass for permission to use the photograph in Plate II; and to Dr. James W. Atz, Dr. Phyllis H. Cahn and Dr. Donn E. Rosen for critically reading the manuscript and suggesting valuable improvements.

\section{INTRINSIC VORTICES}

Since the appearance of the analysis of the hydrodynamics of a swimming fish by Rosen (1959), any study concerned with the approach of one fish to another must necessarily include attention to the possible effects of the locomotor vortices produced by both. Rosen demonstrated, by ingenious means, that vortices form alternately on each side of a swimming fish at the side of the head which presents a concave aspect. These 
appear to pass backwards, nested in the concave areas of the fish's undulations. This apparent movement of the vortices is actually the forward motion of the fish as it insinuates itself about the successive vortices, which themselves remain substantially stationary while the fish progresses between them. See Text-figs. 1 and 2. With the slight oscillation of the fish's head these vortices form alternately on one side and then the other. As a consequence they are spaced just one-half the frequency of the fish's swimming cycle. These alternating and oppositely rotating vortices align themselves in a right and a left line so close together as to mark the track of the fish as a file of contra-rotating vortices in a single wavy line. This is brought about by a complex crossing over from side to side of the vortices around the body of the fish as it moves along, the details of which do not concern the present purposes except to note the following condition. The vortex elements which cross over, and may cross back

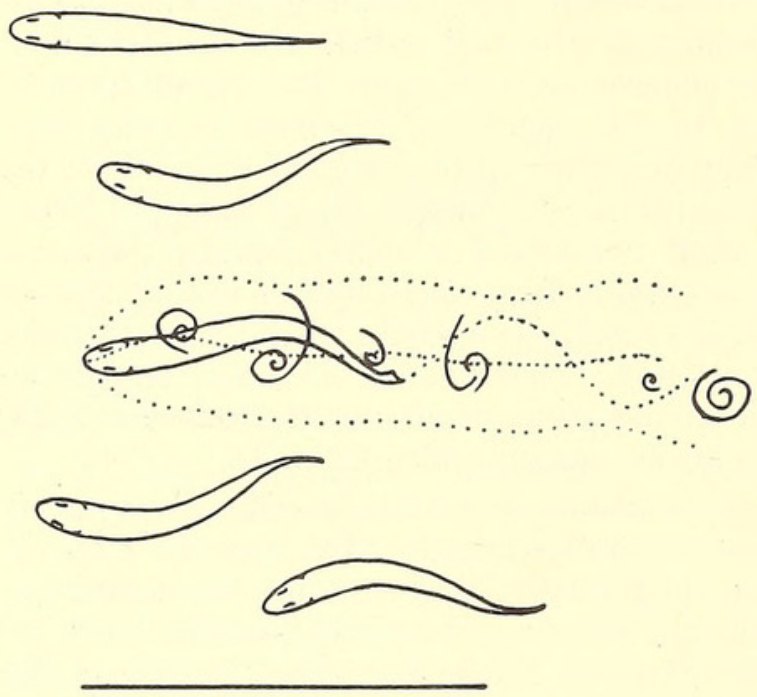

Text-FIG. 1. Diagram of the relationships between a school's spacing and the regenerative vortex flow. The center fish with the flow lines about it has been traced from Figure 24 of Rosen (1959). The added outer two dotted lines indicate the approximate limit of vortex influence. The swirls indicated give only a faint indication of the whole vortex system, as these lines traced from a photograph show only the marks made by their lower extremities because of the manner in which these photographs were produced. Secondary vortices are not indicated. The slightly wavy mid-line indicates the path of the nose. The path of the tail tip is indicated by the mid-line of greater amplitude. The horizontal line at the lower left indicates about $1 / 10$ second. The fish's speed varied from 24.0 to 18.8 inches per second. The other four fishes have been traced from still photographs of the same species, Brachydanio albolineatus, reduced to the same scale, and spaced as they occurred in their school at closest approach. The upper fish is in a coasting position.

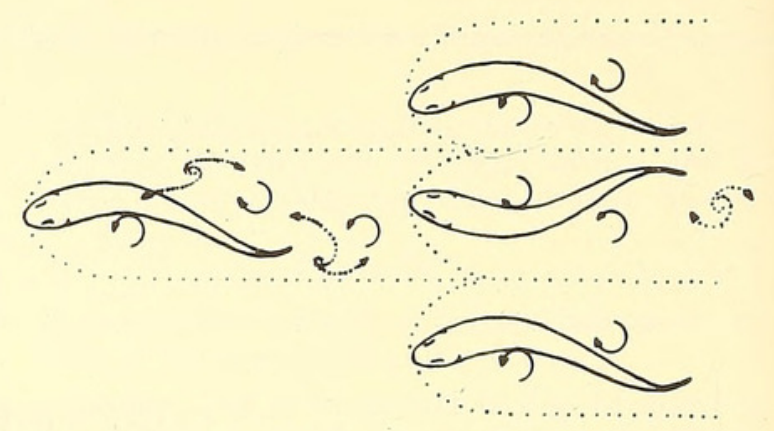

TEXT-FIg. 2. Idealized diagram of four Brachydanio albolineatus, one swimming in the track of another, and one on either side of the latter, beyond the influence of the lead fish. The larger solid arrows near each fish show the approximate positions and directions of rotation of the primary vortices. The dotted arrows show the approximate positions and directions of rotation of two of the secondary vortices beside the lead fish. The dotted swirl at the extreme right, after the following fish, represents a degenerating and mostly spent vortex. For simplicity each fish is shown in the same state of flexure. The open dotted lines, starting at the snout of each fish, show the approximate extent of influence of the vortex necklaces.

again, join the other side of the fish in such a manner that they are all rotating with their forward "pushing" side in contact with the fish in a complicated arrangement of vortices which Rosen calls a "vortex necklace." There is no real wake developed, the vortices simply degenerating where left. The vortices left by a fish rapidly degenerate into what Rosen calls a ". . . twinarmed spiral galaxy which rotates slowly, linking its arm with its predecessor to form a wavy trail. Its pressure has fallen almost to ambient, and it has given up the larger part of the kinetic and pressure energy it once possessed. The velocity of its particles is quite low, and the water in the main arms drifts slowly in alternate directions, largely perpendicular to the fish's path. The energy in these quiet slow orderly spirals represents the energy the fish has expended to propel itself."

Much smaller and less energetic secondary vortices occur which Rosen describes as forming ". . . a zigzag pattern as at the corners of a series of $60^{\circ}$ equilateral triangles. Slightly farther back on the trail [after the passage of a fish] these disappear and the main row of vortices makes its appearance in a single straight line." The secondary vortices evidently have little effect, if any, on locomotion. Rosen points out that this is not a Kármán trail, since that phenomenon covers the formation of a double row of rearward moving vortices formed by the passage of a rigid nonundulating form. These also form alternately and rotate in the same direction as those found 
about a fish. Viewed from above, the vortices to the right of the fish rotate clockwise and those to the left counterclockwise; see Text-figure 2. The lack of a wake formation by fishes undergoing uniform rectilinear translation has also been discussed by Hill (1949), and W. Shaw (1959).

The Kármán trail is stable only if conditions are such that the distances between successive vortices on both of the sides are 3.55 times the distance between the two rows of vortices. This condition exists within a range of Reynolds numbers from about 60 to 5,000 , below which the wake is essentially laminar and above which there is full turbulence. See, for instance, Rouse (1946 and 1963) or Schlichting (1951). Presumably if a fish coasted, holding its body rigid, at an appropriate speed and distance, a common action in many species, a Kármán trail would appear since the complex pattern described by Rosen is completely dependent on the undulations of the fish. From this it follows that the phenomenon associated with rigid bodies, i.e., the Kármán trail, is completely overriden by the onset of undulations. This complex flow pattern Rosen considers a third fluid process, which he calls "Regenerative vortex flow," being neither turbulent nor laminar flow.

Evidently much fish swimming occurs at speeds consistent with the formation of these vortices, that is, at Reynolds numbers above those in which full laminar flow is possible and below those at which extreme turbulence is sufficient to interfere with vortex integrity. This is evidenced by the vortices shown by Rosen (1959) to be produced by a small fish, one and fiveeighths inches long, and by Walters (1962), who made calculations of the Reynolds numbers and the speed above which laminar flow is not found for several of the larger scombroids.

The above does not imply that fishes are necessarily limited to this intermediate range of Reynolds numbers. It is notable, nevertheless, that the speed of translation of a given school slows down greatly when, as in "pod" formation, the individuals give up their usual "standard spacing" and pack together, eventually reaching contact. Here not only are the vortices interfered with, if in fact formation of them occurred at these slower speeds, but in the extreme situation of approach, the boundary layer itself would suffer disruption.

The speed of translation of a normally spaced school is less than the sometimes higher speeds attained by the individuals in it as they "jockey" about. Obviously, if the school is to maintain its integrity the velocity of each fish over a sufficient period of time must be equal. At least some of this position shifting is clearly the result of the attainable speeds possible for given individuals as related to the amount of moment-to-moment impingement of others on the individual flow patterns. This is naturally a very difficult thing to observe directly because of the complex pattern of interacting forces.

One of the problems involved with observing the specific action of currents and other hydrodynamic features within a school of fishes concerns the presence of gill slits on either side of the head which expel water intermittently in accordance with the respiratory activity of the individuals involved. Not only does the presence of these respiratory currents become involved with the boundary layer, but the whole effect is modified by the kind of fish under consideration. For instance, as Walters (1962) indicates, some fishes literally pump the respiratory water in at the mouth and out of the gill slits, as do many of the Cypriniformes and Beloniformes, while others such as the Scombroidei have their respiratory movements synchronized with their swimming motions so that the exhalant water is expelled alternately from side to side always over the side presenting a surface convex to the flow. The vortices form, as previously noted, on the opposite, or concave, side of the fish. The influence of exhalant water on locomotion without reference to the effects discussed by Rosen (1959) was the subject of comment by Breder (1924 and 1925) in connection with the offsetting of cavitation and the maintenance of the boundary layer. Here the shapes of the gill openings were noted to vary in different species, being slit-like in the faster fishes and tending toward the circular in the slower. Thus the long narrow slits of the scombroids, which eject rearward a thin sheet of water along the body surface, were thought to have much influence on the maintenance of an intact boundary layer, while the more circular orifices clearly were nearly a simple jet, the utility of which was almost entirely that of simple jet reaction.

It naturally follows from these considerations that any attempt to further analyze these matters must be undertaken with great care in order to keep distinct the effects of exhalant water from those of the vortices created by the physical movements of the entire body. It is clear that at times the two might work together, as they evidently do in the scombroids, while in other forms the respiratory component might act merely as a disrupting influence, or even be alternating in its influence.

Evidence that these relationships may be very complicated is apparent from the following finding. Six-inch Carassius auratus Linnaeus, when 
photographed with $16 \mathrm{~mm}$. Kodachrome at 64 frames/sec., while swimming in a stationary suspension of bentonite between properly orientated polaroid plates, demonstrated the form and direction of the water emerging from under the gill slits. ${ }^{1}$ In all cinematographic frames in Plate I, left, this flow issued almost on a vertical normal to the longitudinal axis of the fish. It seemed to have an angular divergence of about five degrees to the rear of this vertical, certainly no more than ten degrees. This gave a slight upward thrust to the head which could be clearly seen, in the motion pictures, to be countered by the pectoral fins, which immediately went into what appeared to be appropriate countering action. When this manner of exhalation takes place there would seem to be little interference with the "regenerative vortex flow" of Rosen. Checking on the motions of both the pectoral fins and the fluttering of the opercular and branchiostegal margins of quiescent goldfish under ordinary conditions suggests that more usually they drive their excurrent water straight back and counter its thrust with appropriate pectoral movements. Also, in the case of the downwardly directed flow, there appears to be a slight "pucker" of the branchiostegal basket at its inferior median margin, which is absent when the flow is directed horizontally.

All of the above-mentioned detail cannot be seen in the small run of frames shown in Plate I, left. The exhalant water, however, may be seen as a small dark point, appearing to emerge from the lower profile of the fish just back of the head, seen from the third frame from the top to and including the last and enlarging to a small plume in the bottom picture. The two top frames are at the end of the preceding inspiration. The boundary layer can barely be seen in this series, in which the fish was moving at about 2.7 inches per second. It is much more distinct in the middle set of frames and the right set, where the

${ }^{1}$ These films were taken in 1946 by the Goodyear Aircraft Corporation while they were developing a "water tunnel," planned to deliver good laminar flow in an observation chamber at a considerable range of velocities which could be gradually changed throughout the possible range. The developers of this device graciously permitted the study of these films. The device is now in the possession of the Lerner Marine Laboratory.

Bentonite is a mineral, certain forms of which are composed of microscopic platelets, which are birefringent. Owing to the shape of the platelets, they take on an orientation which is related to the direction and velocity of the water currents in which they are suspended. Because of these two features, when used as described above, bentonite produces a complex pattern of colored bands. Hydrodynamicists frequently have used this material to demonstrate detailed features of complicated fluid flow. fish was moving at 5 inches and 20 inches per second respectively. In neither of these is there any suggestion of a downward exhalation. Evidently in straightforward swimming the exhaled water passes along the sides parallel to the longitudinal axis of the fish. Here it becomes involved with the boundary layer, as previously noted.

The dark, twisted lines in the water which the fish has passed by are evidently the dying "twinarmed spiral galaxies" of Rosen (1959) as seen in lateral aspect. Although the sequences are short, only $3 / 32$ second from first to last, it is clear that these are shrinking features that are not moving in the direction of the fish nor backward from it.

A related feature of respiratory flow, which is sometimes invoked by fishes but usually neglected in such discussions as the present, is that many, if not all, species of fishes can and sometimes do reverse this flow. This has been noted by Townsend (1900) and Breder (1925 and 1926 ) but otherwise seems to have been overlooked. Some specialized fishes have developed the ability to a considerable extent, as, for instance, the Balistidae, which regularly use it to blow sand away from a burrowing crab or other morsel. Other fishes that never do such things can nevertheless expel water from their mouths. Breder (1925) listed 52 species ranging from sharks to balistids which had this ability developed to greater or less degree and indicated that it was least in the sharks and pre-perciform groups, and most fully developed in balistids and plectognaths. Of interest in present connections is the fact that many of the schooling perciforms showed this ability very well developed, including two haemulids, Haemulon sciurus (Shaw) and Anisotremus virginicus (Linnaeus) and six carangids, Caranx chrysos (Mitchill), $C$. hippos (Linnaeus), Seriola zonata (Mitchill), Trachinotus carolinus (Linnaeus), Selene vomer (Linnaeus) and Alectis crinitus (Mitchill). The performances of Toxotes jaculatrix (Pallas) are probably little more than an extreme specialization in this detail of behavior.

Since the behavior of water flow concerned with all the preceding discussion is determined by the speed of translation of the fish and the viscosity of the water, values that determine the Reynolds number, it should be noted that since the viscosity of water varies inversely with its temperature, this might be supposed to have some influence on these features of fish locomotion and aggregating characteristics. The influence which viscosity variation might have on such behavior, within tolerable ranges for any one kind of fish, would, however, not be ex- 
pected to be great. Experimentally, water could be so treated as to increase its viscosity greatly by the addition of some inert material such as methyl cellulose. Since these conditions do not occur in natural waters, although such experiments might easily show important locomotor details, they would be too far afield from present purposes to include here. It is not known what effect a distinctly greater viscosity would have on schooling, but it is most probable that the problem of locomotion under such different conditions, with which a fish could not have had prior experience, would result in suppression of schooling and if the viscosity was extreme enough, would result in complete locomotor disorganization.

No effort has been directed toward measuring the relationship of Reynolds numbers to swimming speed under various conditions of temperature. At best, the many other physical and biological reactions that are affected by a change in temperature would be difficult to distinguish from the strictly locomotor. However, in other connections, the rate at which a goldfish can swim steadily at different temperatures, to which it has become adapted, has been measured by Fry \& Hart (1947). This rate rises rapidly from $5^{\circ} \mathrm{C}$. to about $20^{\circ}$ where it flattens out to about $30^{\circ}$ at which point it falls off rapidly to the highest temperature measured, $38^{\circ}$, clearly close to the fish's limit of tolerance. This curve surely represents the results of many temperature-induced biological effects, some of which are evident, but the decreasing Reynolds number would seem to be one component of the totality of effects, especially in the limb of the curve from $5^{\circ}$ to $20^{\circ}$. Separation of all the influences would not be easy.

These items need not concern the present study particularly since all that is needed here is an understanding of the total influence of each fish on its near neighbors. However, a recognition of these details of the nature of the components comprising the total locomotor effects should help make some of the matters directly relevant to present considerations more readily understandable.

As the efficiency of this type of undulatory locomotion depends on the integrity of the fishproduced vortices, it follows that fishes swimming close together must do so in a manner that respects these vortices or suffer a considerable reduction in their locomotor efficiency. Because fishes in a school normally maintain a standard distance between each other, the following experiments were performed in order to determine how this standard distance is related to the size and location of the vortices.
Most small cyprinids will form temporary fright schools on slight provocation, a feature sometimes useful in a study of aggregations, for instance, see Breder \& Halpern (1946). They used Brachydanio rerio Hamilton-Buchanan, which readily forms very tight schools on such occasions. Rosen (1959) used the closely related B. albolineatus (Blyth). Experiments demonstrated that both species reacted in an essentially identical manner under identical conditions.

A series of electronic flash still pictures were taken of aggregations of both species at their tightest grouping. From these photographs, pairs of fishes, (B. albolineatus), showing the closest approach, as they formed schools, were selected for reference to the diagrams Rosen (1959) based on the same species for his locomotor studies. Text-figure 1 shows a tracing of one of Rosen's diagrams (his Figure 24) based on several successive frames from his high-speed cinematographs and compared to fishes from the fright group direct from our still photographs, all reduced to a common size. This figure indicates clearly that the "regenerative vortex flow" patterns of each fish would not encroach on the active portion of another fish's trail so long as they did not approach each other more closely. This may be merely a standard feature of this particular species or a general primary situation in the formation of schools. These, and other observations, indicate that the side-to-side spacing of fishes in a school is usually just a little over twice the distance from the side of a fish to the outer edge of the trail of vortices in the area of their production. This insures their integrity until the fishes have left them behind. As the maintenance of the integrity of these vortices is important to the efficiency of the fish's locomotor efforts, this may be the controlling factor that determines how closely fishes in a school approach each other.

An equation for characterizing a fish school on a basis of the fish-to-fish distance was developed by Breder (1954)..$^{2}$ Comparison with the fishes used in that study ( $\mathrm{d}_{1} / 1$ of that equation) shows that Brachydanio albolineatus fits well in this group $\left(\mathrm{d}_{1} / 1=0.30\right)$. Table $\mathrm{I}$ indicates that this measure can vary between 0.16 and 0.55 on the basis of such measurements on a sample of diverse species. This situation suggests that the

2The equation follows:

$$
\mathrm{c}=\mathrm{a}-\left(\mathrm{f}_{1} \mathrm{p}_{1}\right)\left(\mathrm{f}_{2} \mathrm{p}_{2}\right) / \mathrm{d}^{2}
$$

where $\mathrm{d}=$ distance between individuals; $\mathrm{f}=$ number of individuals; $\mathrm{p}=$ potential of each individual; $\mathrm{fp}=$ repulsive force; $\mathrm{a}=$ attractive force $;$ and $\mathrm{c}=$ a measure of the cohesiveness of the group. Where all p's are equal, as in most normal fish schools, they may be dropped. See the original paper for full details. 
preservation of these vortices may be the demand which determines the inter-fish distance. If so, the " $\mathrm{d}_{1} / 1$ " of the equation becomes not less than one-half the distance a fish must keep between itself and its nearest fellow in order to preserve the integrity of both sets of vortices.

Similar measurements of the spacing in a run of tuna, Thunnus thynnus (Linnaeus), from a photograph, Plate II, taken eight miles south of Cat Cay, Bahamas, indicates that the spacing of these individuals is proportionally greater than in any of the smaller fishes so far measured, $\mathrm{d}_{1} / 1$ being not less than 0.50 . If the vortex trails are primarily responsible for the spacing of fishes in a school, this condition would not be unexpected, that is, as size increases, the distance necessary to maintain the integrity of the vortices also increases, but faster than the length increment.

By comparison, a very tight school of juvenile Mugil cephalus Linnaeus ranging on a sandy shore showed $\mathrm{d}_{1} / 1$ to be not less than $0.03+$, see Plate III, lower. The tuna averaged about 6 feet in standard length and the mullet about one inch. The measurements of the mullet's distance is the smallest so far determined. In these tight schools there is not much forward motion and the individual speeds of each fish may well drop to a figure at which vortex trails do not form at all. Whenever fishes in this school had cause to increase their speed, there was always an accompanying increase in the distance between them, as can be seen in Plate III, lower, where a small marginal group has started to accelerate with an increase of $\mathrm{d}_{1} / 1$ to about $0.17-$ which is not far from the average of small fishes of other species previously measured. It should be noted that Mugil cephalus is the species which so frequently forms tight pods in which the fishes actually come into contact and with minuscule forward motion. No mullet of the size here discussed has been seen to form pods and the present picture represents the closest approach to pods by true schools so far encountered in these studies.

The preceding discussion is concerned only with the side-to-side relationships of fishes in a school. The relationships of fishes following others are somewhat different. Since there is no wake, the only hydrodynamic influence of any moment to be expected would have to come from the dying vortices remaining in a slightly staggered row. As these subside rapidly it would not be expected that they would be of any considerable influence. However, it is nonetheless a fact that in many schools the individual fishes appear to avoid a head-to-tail, single-file, swimming habit. See, for instance, Plate II. Here, in a school of nearly 100 tuna, not more than four can be seen in such a position. While the positions of individuals are more or less continually changing, this situation is common in schools of many diverse species of fishes. In the singlefile, follow-the-leader, position the trailing fish should receive whatever residual energy that may be left in the expiring vortices of the lead fish, as is indicated in Text-figure 2. Such energy would have its influence at primarily right angles to the course of the fish, alternately left and right. The secondary vortices at this time would not be expected to be influential. Further to either side the trailing fish would be out of the possible range of hydrodynamic influence of the lead fish. The position where a definite retarding influence would be felt, indicated by dotted lines in Text-figure 2, is precisely the position in which fishes are not apt to be found in a school unless they are further to the rear of the lead fish than those shown. As is clearly indicated in the figure, the fish would be swimming into the "wrong" side of the vortices. This distance may, in fact, be a measure of how far rearward there is any energy left in these vortices.

The evidence shown here for the existence of these locomotor vortices gives a more solid basis for the general views, more or less vaguely expressed, of inferred benefits to be derived from birds and fishes progressing in groups. The well known "V" formation taken by many species of birds in flight and the staggering of individual fishes swimming in groups has been noted by many, for instance Breder (1926) and Matschinski (1953).

The remaining dimension to be considered, that of fishes arranged in a school of more than one layer deep, again presents another situation, different from the two horizontal dimensions. Since the fishes undulate from side to side, these two dimensions are the ones directly involved. The only disturbance present in the third dimension is incident to the vortices crossing over from side to side about the body of the fishes as indicated in the diagrams of Rosen (1959). This disturbance is slight and fishes swimming in many layers do not regularly leave as much swimming room above and below themselves as they do in either horizontal direction.

Obviously fish schools vary widely among different species and in one kind under varying conditions. Thus schools such as those shown in Plates II through IV, while common enough, are sometimes replaced by fishes swimming closely head-to-tail in long trails. Such groups are not very common nor well understood. It is thought though that this type of behavior is not especially related to locomotor convenience, but to other biological necessity. 
Sensitivity to the water movements induced by other fishes might be conceived of as being mediated proprioceptively through necessary changes in muscular tension accompanying changing swimming efforts in response to current changes. This would, of course, be in addition to the optical response, as the speed of passage changes the view in accordance with small accelerations and decelerations. In addition, most fishes are abundantly supplied with special sensory devices involving the whole lateral line complex. Moreover, van Bergeijk (1964) indicated that apparently the lateral line organ is employed as a near field acoustic detector and the swim bladder-ear system as a far field detector. This is in keeping with the view that the lateral line cupulae are primarily displacement receptors. Located as they are, it would be strange indeed if they did not supply cues about water movement. It would seem that the multiplicity of possible information paths gives a measure of the importance of cues in this connection and could conceivably go far in its totality to account for the more remarkable unanimous wheelings and turnings of large schools. The above would in no way invalidate the ideas that aggregations in the dark may be prevented from wandering too far from each other by means such as auditory cues as, for instance, indicated by Moulton (1958). Only the serried ranks of schools being fully dependent on vision would disappear. The general ability of fishes to avoid obstacles in the dark by sensing differential water pressures should keep them from collision.

A close inspection of Plate III, lower, reveals a series of thin, light, wavy lines above the school, especially prominent over its highest point and running similarly to the left almost to the rather pointed left and tail end of the school. Lesser similar lines are to be seen adjacent to other margins of the school. It is to be noted that at no place remote from the school do these lines appear. This condition was found to be the case in the dozen other photographs made of this school during this one observation session. No other photographs taken by or seen by the author have ever showed this feature. It is believed that the appearance of these lines is caused by refractive peculiarities induced by some unnoticed optical circumstances present at the time these photographs were taken. Examined in relation to the degenerating vortices shown in Plate I, it is thought that these are the composite water disturbance induced by the whole group. It is also to be noted that no such features are to be seen at the advanced, right end of the school, where they could not be formed in any case.
It was mentioned in the Introduction that only schools would be discussed in detail. The reason for thus limiting this paper is that the present state of knowledge of the influences of fish-generated vortices over distances greater than those found in schools is nil. If there is any energy at all left in them by the time they are reached by another fish in a non-polarized aggregation, it is not detectable by present methods. Thus, it is not considered profitable to go into such a speculative area at this time. The effects, so far as known, in what Breder (1959) considered as unstable internodal positions between school and pod, have been discussed in the preceding paragraphs.

Another, and related matter, which will not be taken up, is that of the approach of schools to the surface, bottom or solid obstacles. Again, there are so little data on the hydrodynamic aspects as to preclude little more than bare speculation. It is noteworthy, however, that the approach of schools to the surface or the bottom is much less restricted than to vertical solid surfaces. This would seem to relate, in part, to the fact that the water disturbances produced by fishes are primarily lateral, because of the geometry of their propulsive mechanisms. Plates III and IV, especially, indicate the lack of reluctance of various types of schools to approach surface or bottom. The much greater reluctance to approach solid objects laterally is especially noticeable about piles. A considerable amount of this reaction is mediated through the optical system. It has been shown, in one species at least, that approach to a light-colored object will be closer than to an otherwise identical but dark object, Breder (1951). In this case the fishes approached the dark surface to within about one and one-half times their own length while they approached the light surface to about half of that distance. Because of this condition and the general complication of the situation, as well as the inherent difficulties in trying to establish the hydrodynamic values contributing to this behavior, if, in fact, any are involved, it is, again. rather beyond present means of detection.

\section{EXTRINSIC VORTICES}

The term "extrinsic" is here used to cover vortices that have influences on fishes, other than those intrinsic to the locomotor activities of fishes themselves. They cover all the physically caused vortices, most usually those created by water currents. Commonly such are to be found in flowing water where the presence of various kinds of obstructions develops viscous shearing forces that lead to various degrees of turbulent flow in which the vortices are swept along, or to standing vortices where eddy formation occurs. 
In the case of a rapidly flowing stream, such as a typical trout stream, flow at a given point may vary from the almost laminar, through intermediate stages to the violently turbulent. Speed of flow and the geometry of the situation determine the particular condition found. Superficial observations show that fishes are forced to adjust their locomotor activities according to the conditions. Thus, in a nearly laminar flow of a sufficiently sluggish current, fishes may be seen rather easily stemming the current at an equal and opposite speed and holding a place, either as a solitary individual or as a stationary school, sometimes for long periods. A valid verification of the character of the flow can usually be obtained by observing the paths of fine particles, either naturally present or artificially supplied. In cases where the speed of flow exceeds that at which essentially laminar flow is possible, the aquatic equivalent of "dust devils" may be seen under certain conditions where the flow passes over a fine sand bottom. These are, of course, caused by vortices resulting from separation of boundary layers around some obstruction, upstream from where they become noticeable. Actually, such a stream is more or less filled with Kármán trails which interact with each other in a complex fashion that is not easily recognized by simple observation. Because of the speed of flow and the complex nature of the vortices being swept along in series, ordinary swimming becomes impossible. Under such conditions fishes are to be found stationed behind some large rock or other sheltering obstruction. From time to time they may dash out into the flow and zigzag at great speed to some other sheltered spot further upstream, or drop downstream, while heading into the flow, to some other retreat. Although it is difficult to prove by direct observation, every appearance indicates these zigzag sallies in such fast flows are conditioned by the presence of vortices passing downstream within the general flow. It would seem likely that the fish are taking advantage of the lessened flow downstream on the side of the vortex which is moving countercurrent. In fact, taking advantage of these features may be the only means by which such fishes are able to negotiate flows as strong as they can be observed to negotiate. At least, when the flow becomes truly turbulent, as can again be checked by the erratic movement of particles, most fishes do not even try to buck the flow. Under these conditions only relatively large fish ever hazard such attempts.

\section{The Fish Mill as a Vortex}

The fish mill, a closed-figure fish school, first analyzed by Parr (1927), was considered by him to be a structure in which schooling fishes are sometimes trapped, which remains in one place, while all the fish follow each other in a more or less circular path, until some exterior event breaks up the formation. Parr described the conditions under which a mill could form in accordance with his observations. This is no doubt about the manner in which schools are frequently formed, but since the time he studied the subject, data have been obtained which indicate that there are, in addition, other causes leading to mill formation, perhaps many.

\section{Types of Mills}

\section{Extrinsic mills.}

Parr's mill.-The mill formation described by Parr loc. cit. may be briefly defined as depending on some extrinsic agency, such as an obstacle, deflecting the anteriormost members of a normally advancing school so that they see the posterior members and turn to join them. This act closes the circuit and forms promptly into a typical circular mill.

Flow pattern mill or current-induced mill.Wherever a flow encounters a projecting obstacle, a standing eddy forms in its lee. Under certain circumstances these may be of considerable stability, as simple field observations can substantiate. Sometimes mills of fishes are to be found circulating in them in a direction always opposite to that of the circulation of the water as indicated in the preceding section. It is easy to imagine how such fish mills could be established, but quite another to provide it rigorous proof. Apparently all that it is necessary to postulate is a school counterswimming the main flow in the neighborhood of an eddy. If the school should approach the shear line between the eddy and the passing main stream, the tendency of fishes swimming countercurrent to seek quiet waters after a time of stemming a swift flow could account for the school inching over into the less rapid induced flow and forming a mill concentric with the eddy.

Special cases.-Various activities of man sometimes cause the formation of fish mills. These may be induced in manners identical with those described above, usually by engineering work involving modification of shore lines or other changes in features of the physical environment. Other types of man-induced mills may form on novel bases not previously possible. It is well known that strong lights placed close to the surface of the water or submerged, sometimes for the purpose of attracting fish, may induce mill formation by those attracted. Such a mill will have the light at or over its center; see, for instance, Miyadi (1958). The mechanism involved here is too obvious to warrant comment. In this 
case the mill is pinned down to a stationary position in relation to the light, for such mills disperse on extinguishing the light or can be made to follow the light if it is moved about slowly.

Intrinsic mills.

Viscous shear mill.-Mills often form when there is no obstacle or other evident extrinsic influence on the leading members of an advancing school. Such a condition was described by Breder (1959) as being observed in schools of young Ictalurus. Since then further observations have been made on similar behavior of approximately three-inch Mugil cephalus. It was possible in one instance to take serial photographs of the process which show the essential action. Plate IV shows a rather infrequently seen form of intrinsic mill formation. This is apparently the only photographic evidence that a forwardmoving school, through very quiet water and with clearly no exterior interference, will so behave. This action was photographed in a tidal basin, thirty feet in diameter, in almost the slack water of high tide. The school happened to be heading into the flow as the first photograph was taken. Previous to this, it had been wandering about in various directions. At no time did it approach the shore closer than is indicated in the photographs, by the foreground grass-heads. A very light breeze was gently riffling the water surface from the upper right. That this had nothing to do with mill formation is clear, because the same action has been witnessed in dead calms. In fact, in the perhaps dozen times this particular type of mill formation has been seen, it has mostly occurred in extremely quiet water. The impression has been that the slightest exterior influence would completely inhibit the behavior. The present case happens to be the only instance when it was possible to make such pictures in rapid succession.

The exact forces at work are still not certain, but may well be associated with a shearing action within the school that develops when irregularities appear in a school of fishes advancing in closely parallel rows and, in terms of hydrodynamics, behaving almost as a simple laminar flow. In the formation of a fluid vortex evidently both viscous shear and inertial effects are involved, see Rouse (1963). That he questions some of the current theory involved does not, however, concern present purposes, for whatever the outcome it would not alter the possible effects of the fish-generated vortices. Prandtl (1904) showed that the occurrence of such perturbations of a sheet-like flow can only lead to amplification, so for the implied convergence of the streamlines involved, according to Bernoulli's theorem, there must follow a rise in velocity and a drop in pres- sure, leading to further asymmetry of the flow, and finally to a series of vortices. Because of the sizes of the fish schools that have been under observation, hardly more than one vortex could be expected in a single school if the formation of an intrinsic mill follows these hydrodynamic principles. Perhaps if two started to form, one would neutralize or engulf the other.

Sparring mill.-While peck-order is evidently almost negligible or absent in the most persistent schoolers, there are other fishes that form "fright" schools or other temporary aggregations. Such a case would be illustrated by Astyanax, discussed at length by John (1964). He described two fish circling each other, in the absence of other individuals, and indicated that this could be the beginning of school formation. It might, however, be quite the contrary, and actually represent the "sparring" of two antagonistic individuals in a somewhat "stylized" manner. If this type of behavior ever occurs between two individuals in a large school and leads to mill formation, it has not been recognized, for there have been no such instances reported.

Bearing on the above are the studies of Okuno (1963), who, by means of studies in the sea and in large and small aquaria, reported that fishes which formed stable schools in the sea and in the large aquaria did not pursue one another in small aquaria, whereas all other types showed some sort of pursuit of their own kind or of others. The latter included types that formed unstable schools similar to those of Astyanax.

\section{General Considerations on Mills}

Since it might not be apparent that there is an adequate justification for comparing the purely physically-induced movements of fluid particles with the biological activity of swimming fishes, the following explanation is given. No objection would be expected from the hydrodynamicists, as they have no qualms about comparing the flow of automobiles along a highway with the flow of water in a stream.

As all biological activity is restricted by the physical limitations of the organism as well as the physical limitations set by the environment, it is generally useful to assay a given situation as to what part of an organism's activity is rigidly enforced by the environment and what part is further limited by the constitution of the organism. This then makes possible a determination of what might be called an organism's "degree of freedom." These differences are not always easy to distinguish except in a gross way, but one of the present purposes is to attempt to delimit what part of schooling is forced on a fish and what part is subject to adjustment by the individual. 
The latter portions of the observed behavior would be expected to be those showing the greatest variations in environments that, while seemingly identical, reveal fishes doing a number of different things, whereas the most rigid and stereotyped behavior would be suspected of being a mandate primarily imposed by immediate physical necessity.

A fish school does not form because of a center of attraction, but by the mutual attraction of each fish to others. Fish mills, however, may be formed by exterior or interior perturbations, as previously indicated in the list of types of mills. Only an intrinsic mill evidently is formed because of a central disturbance, which may be comparable to the hydrodynamicists' viscous shear in the generation of vortices. Breder (1951) showed that a mill of Jenkinsia rotated, with the nearly axial fishes swimming much more slowly than the peripheral ones, but that there was much slippage between members, so that, although the peripheral fishes were moving faster than the nearly central ones, the school was not rotating as though it were a solid wheel. Fish mills resemble standing eddies rather than a wash basin vortex or a hurricane. Because the rotational flow of standing eddies is induced and maintained by the influence of the passing flow along the shear line, it follows that flow of the eddies is moving fastest at their peripheries and slowest near their centers of rotation. This feature resembles that of the mill just noted. At certain rates of flow and conditions of turbulence of the passing stream, the eddy breaks up in an irregular series of smaller eddies moving along the shear zone, as a form of Helmholtz instability. Only under certain conditions, involving the geometry, the rate of flow and the viscosity, will a fairly stable eddy be formed.

Vortices of all sorts are controlled by inertial and viscous effects, which are in opposition to each other, the first tending toward eddy formation and the second tending to dampen eddy formation and leading to eddy destruction. If it is proper to refer these effects to a fish school, this would imply that a school continues in its direction of motion until it is altered by some influence, which could be either extrinsic or intrinsic and that all retarding effects interfere with the integrity of the group. Obviously this statement could be rewritten for a single fish and it would be equally valid, but probably not worth saying. However, in connection with a group and the formation of mills it holds some interest. If the cohesiveness of the school be equated to viscosity, we could then discuss the formation of intrinsic mills in terms of viscous shear and inertial effects. This could involve a study of the relative strength of the forces of cohesion from fish to fish and the readiness with which a fish transfers from immediate companions to others. It could also consider the relative influence of small differences in the deployment or in the potential of companions to the right as compared with those to the left of a given individual. It is at this level of integration where intrinsic mill formation should be expected to develop. Possibly here, too, a distinction could be made between inertial and viscous effects. They might appear respectively as overshooting companions or as laggards. This would also be the equivalent of an overly sensitive and consequently overshooting pen on a paper tape recorder as compared with one that is sluggish because of overdamping. Probably in a given school the individuals are in a fairly narrow spectrum of degree of reactivity. These differences in reactivity would be expected to be distributed according to some more or less normal frequency, with the bulk of the individuals showing the peak occurring near the mean or mode with many fewer at the high and low extremes. If this is in fact the case, then one would expect the comparatively few high and low reactors to have much more influence on alterations in the behavior of the school than the large numbers with intermediate reactions. This small extent of behavioral variation probably measures the amount of information present in such a school, which is obviously a system of great redundancy.

Pertinent to the preceding comments on the behavior of fishes within a mill, but also common to all schools, is the easily observed feature that the fishes which comprise them do not retain fixed positions relative to each other but are more or less continually "jockeying" from one position to another. One apparent reason for this is evidently that they are all adjusting their speed at any moment to that of their nearby neighbors. That schooling fishes do not adjust precisely to moving targets has been nicely shown by Shaw \& Tucker (In Press). They used an opto-kinetic device in which a circular targetbearing drum rotated concentrically around a transparent circular tank. The target was a dark band on an otherwise immaculate surface. The fish to be tested were placed in the tank and would follow the band around through a considerable range of speeds, a fact that has been known to be the reaction of a variety of fishes. In this case records were kept of the locomotor behavior of the fish under test. At a given uniform speed of target, one species, Caranx ruber (Bloch), tended to overshoot the target, that is to swim around the aquarium a few more circuits in the time alloted than the drum rotated, while another, Selar crumenopthalmus (Bloch), 
lagged slightly behind the speed of the drum. It is noted that the first-mentioned is a considerably faster-swimming fish. The difference in behavior may well be caused by a conflict between the tendency to follow a moving object with that to swim at a speed relative to the species' natatorial ability, its size and the extent of fatigue. This effect, by itself, would seem to be sufficient to account for the continual adjustment commonly seen in schools.

If the effects of the trail of vortices be added to the above influence, in which individual fishes are slowed down momentarily by running into the "wrong" side of the vortices produced by some other fish as against those which happen to run into the "right" side of such vortices, there is an added purely mechanical factor tending to produce irregularities in the velocity of the individual fishes. This, however, should contribute little to variation in the forward velocity of the school as a whole, since these differences should be largely symmetrical and consequently self-effacing.

In the case of great differences of size of individuals swimming together, as pilot fishes (Naucrates) with large sharks, the situation is apparently different. Shuleikin (1958) reasoned that when a shark is moving rapidly the pilots could not possibly keep up with it unless they occupied positions within the boundary layer of the shark and were thereby swept along. Obviously, they are not so restricted when sharks are moving slowly. Whether the "regenerative vortex flow" of the shark also enters in as an assisting agent has not been studied, but it would seem to necessarily follow that it would, at least at some times. This entire matter suggests the need of further study as no one knows how long a pilot fish will stay with a given shark or whether the latter frequently loses its attendants when swimming for long distances at high speed.

\section{DisRUPTION OF Vortices and SCHOOLS}

The disruption of mills and vortices by fright or violent disturbance is sufficiently obvious not to need elaborate discussion at this point. However, it may be noted that acceleration of fluid flow will destroy a vortex and prevent vortex formation and lead only to violent turbulence. See Rouse (1963) for a discussion of these features and those of "viscous decay" and inertia. Mild fright will usually cause first a sudden acceleration of the individuals in a mill or school and then lead immediately to disruption. Without pushing this resemblance too far it may be noted that in both fluid flow and fish assemblages, return to the prior condition is normally prompt. Plate III, upper, shows a school of three-inch
Mugil cephalus exploding in fright at the near passage of a kingfisher. This school had formed a mill, as might be inferred from the radial arrangement of the dispersing fishes. In a school that is not a closed figure, the usual dispersal lines merely fan out from the advanced end of the school. This is the same school discussed under Viscous shear mill and illustrated in Plate IV.

The velocity of advance of a school, as indicated earlier, must be precisely related to the velocities of its constituents. If it is not, the school disintegrates. There is evidently a range of possible speeds of translation of the school as a whole, only within which it is possible to maintain an intact school. Below some critical speed of school advance, in still water, it would appear that spontaneous individual differences in orientation, without the steadying effects of sufficient forward motion, are insufficient for the maintenance of polarization. At this point the school dissolves to an aggregation. The same situation obtains in a stream flowing past a "standing school."

At the higher velocities attained by schools, as with a burst of speed, there is usually a considerable loosening of the school and often complete disorientation as well, as in Plate III, upper. Bursts of speed in a school almost always follow a fright and are usually otherwise absent except in the planktonic feeding of some forms. At these times it is difficult, if not impossible, to discern how much the loosening is referable to a "general dispersal response," and how much is referable to the locomotor demands of the increased speed.

Bainbridge (1958a and b) and Bainbridge \& Brown (1958) have shown that, in fishes employing undulatory body movements for locomotion, at least, an individual twice the length of another will travel twice as far if the frequency of their tail beats is identical, according to the formula:

$$
\mathrm{V}=1 / 4[\mathrm{~L}(3 \mathrm{f}-4)]
$$

where $\mathrm{V}=$ velocity, $\mathrm{L}=$ length of fish, and $\mathrm{f}=$ frequency of tail beat. This relationship evidently holds for fishes up to 12 inches in length and perhaps considerably larger. It is assumed that such comparisons are to be made between fishes of like species and condition and that the amplitude of the tail beat is equivalent. These conditions very probably suffice to restrict the variability in size of the fish in a school to the small ranges that have been observed. Measurements of the ranges of the length of fishes, given as ratios within a school, of the smallest to the largest member, have been made by Ohshima (1950) for Plotosus anguillaris (Bloch) 0.65, Schaefer 
(1948) for Thunnus albacares (Bonnaterre) 0.73 to 0.50 with a mean of 0.61 , and Breder (1951) for Jenkinsia lamprotaenia (Gosse) 0.61. Some of these are evidently extreme because of the methods used, for at least in Thunnus there may have been portions of separate schools inadvertently mixed in their capture. It is to be noted that the first and last species are within the range shown for Thunnus and that Ohshima found that schools broke up if the range he gave for Plotosus was exceeded. These data together with similar measurements on other species are given in Table I.

It would seem that as differences in the lengths of fishes within a school approach the condition where one individual would be twice the size of the others, schooling no longer occurs. This is also the point at which the larger is able without special effort to swim twice as fast as the smaller. Certainly no stable school of a homogeneous kind with such a size range has been reported. It is also notable in this connection that Bainbridge (1958a) indicates that the ability of fishes to sustain periods of swimming is proportional to the length of the fish, but is related to it differently in different species.

The adjustment of differences in speed can ordinarily be easily seen in most fish schools, the slower ones increasing the frequency of their tail beat as well as increasing the amplitude of the tail's oscillation. Fishes outrunning the others sometimes adjust by merely swimming slower, but most frequently simply "coast" by holding their bodies straight until the speed is suitably slowed, as is indicated in Text-figure 1 by the posture of the upper individual. Evidently such accommodation to one another's normal pace is not acceptable beyond the size limits indicated in the preceding discussion and may be one of the primary causes of school dissolution. Since, so far as known, schools become aggregations in complete darkness there may be a considerable amount of re-formation and dissolution with the return of light, resulting in the degree of uniformity ordinarily found in schools by the time it is light enough to make satisfactory observations under the usual field conditions.

Related to this but at the opposite end of a series are the cases where different species of fishes mingle as one group in certain parts of their life history or under certain conditions of environment. Such a case for Girella punctata Gray and G. melanichthys (Richardson) has been reported by Okuno (1962) where the young of both species form common schools in the middle parts of a bay but keep separate in all other localities. This would seem to be related to the conditions found with the cyprinid Note- migonus crysoleucas (Mitchill) and the catostomid Erimyzon sucetta (Lacépède) reported by Breder (1959). Here the young fishes aggregated or schooled during the daytime but passed the night in separate places. The opposite of this was also reported in the same paper where two kinds of fishes (Jenkinsia lamprotaenia and $\mathrm{An}$ choa hepsetus (Linnaeus)), very similar in appearance, to human observers at least, firmly maintained two tight and separate schools. What visual differences caused them, at the distance at which they turned, to avoid one another is still unknown.

If the minimum normal swimming distance between side-to-side fishes in a school is listed according to the absolute size of the individuals a rather interesting relationship may be established. It is much easier to take photographs of a school from above than to obtain precisely accurate measurements of the individuals in the same school. Therefore, the listing shown in

\section{Table I. Ratios Characteristic OF Fish SCHOOLS}

First column, species arranged in terms of rank of absolute size of fishes, from smallest to largest; second column, ratio of fish lengths to minimum distance apart of fishes in a school; third column, ratio of smallest to largest fish in a school.

\section{SPECIES}

Distance

Between

Size

Ictalurus nebulosus ........ 0.20

Mugil cephalus ........... 0.17

Brachydanio albolineatus ..... 0.30

Jenkinsia lamprotaenia . . . . . . 0.25

Atherina stipes .......... 0.18

Sardinella macropthalmus .... 0.16

Selar crumenopthalmus ...... 0.49

Strongylura notata ........ 0.55

Thunnus albacares ........ 0.50

Ratio

.

$\cdots$

0.76

0.75

0.87

.

0.612

${ }^{1}$ From Breder (1954). Another school, under other conditions; Breder (1951) gave a value of 0.61. Other data except as noted below are from Breder (1954) or are new. Plotosus has been omitted from this table and Text-figure 3 , because of various difficulties in interpreting the data.

${ }^{2}$ From Schaefer (1948). This figure is a mean of a number of schools which varied from 0.73 to 0.50 . On the basis of the other data it would seem that the lower figure must represent a very unstable school or perhaps two separate schools mixed in the catching. Although the figure is included here, as the only one available, it is doubtful that it is valid for present purposes. No values for apparently normal schools of the interfish distances were obtainable and size ratios extended from groups ranging from 6.2 to $4.9 \mathrm{~cm}$. with a size ratio of 0.79 to one of 2.3 to $1.8 \mathrm{~cm}$. with a size ratio of 0.78 . However, there were three intermediate groups which had size ratios extending from 0.74 to 0.78 . Some of these groups would be in the second place and some in the third and fourth places in this table. The insertion of these data would not modify the opinions expressed herein. 
Table I has been arranged according to rank of absolute size of fishes named, a matter that is relatively easy to estimate with great accuracy. When these data are plotted as in Text-figure 3, it is at once evident that distance between fishes in a school approximates a linear relationship between the length of the fishes in terms of rank order and the minimum distances between the individuals comprising a school in terms of percent of fish length. Although the scatter is considerable, the graph reaches over a range of lengths of about one-half inch to about five feet or more. This may be a measure of the increase in the diameter of the vortices. Perhaps the scatter is no more than should be expected when the diverse nature of the body forms of the fishes included is considered. Included in Text-figure 3 is a comparison of the range ratio of fish lengths compared with the absolute size rank. Here, as would be expected, there is no evidence of a drift with increase in length of the fishes concerned.

Other more obscure features may be perhaps best illustrated by the following observations made on feeding groups of young Mugil cephalus about $25 \mathrm{~mm}$. long. When feeding vigorously in shallow, clear water, the following sequences may frequently be seen. For example, a group of about one hundred such fishes was seen feeding, on the bottom, with the peculiar side-to-side movement of their heads as they scraped algae off stones and shells. At such times usually not more than half the number were engaged in this feeding activity. The non-feeders would be found to be above the feeding group as a random aggregation. Mostly they would be very quiet but one might make a short swimming movement of about twice its length, at which one after another of the non-feeders would line up and follow the first, forming as they did, a proper school which would then stream off as a long, thin school, perhaps for a distance of twice the original school's diameter, and then settle down and feed. It seemed as though the first fish which initiated the school would swim away from the group as a consequence of the others all swimming toward it and not that this initial fish separated from the feeding group of its own activity. The other half (the feeding half) paid no attention but continued feeding until it had probably removed most of the edible portions of the area. At this time they would stream off as a school and settle on a new spot to again scrape algae as a loose aggregation. After these settled it was noticed that not all were feeding and like the previous group about half were stationed above the feeders. Since this whole group contained only about 50 fishes, the 25 non-feeders which streamed off to find another feeding ground were about one-

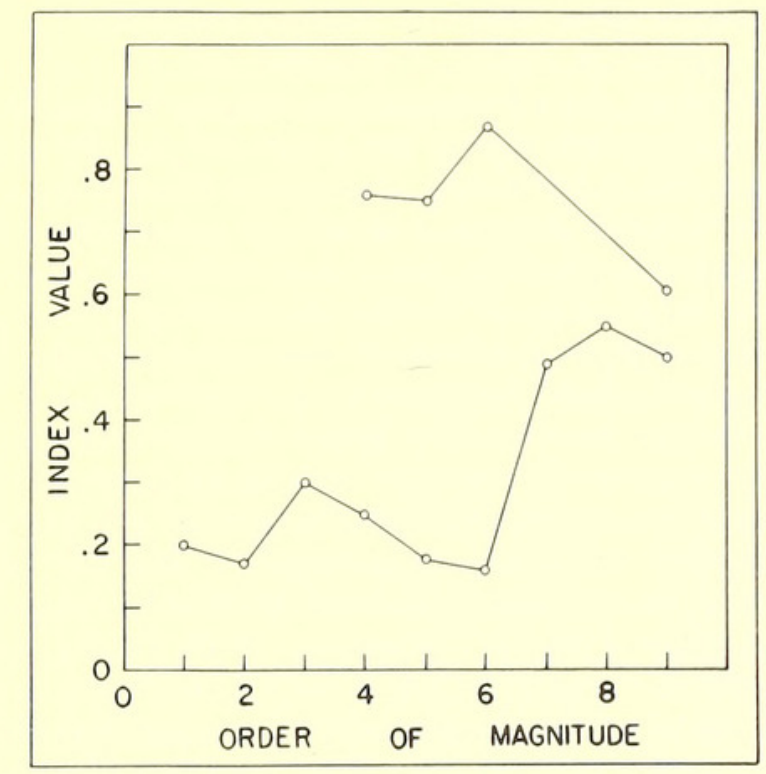

TEXT-FIG. 3. Ratios characteristic of fish schools. Order of magnitude $=$ Lengths of fishes in order of rank. Index value for lower line $=$ ratios of fish lengths to minimum distance apart; for upper line $=$ ratios of largest to smallest fish in a school. See text and Table I for full explanation.

quarter of the original group. This same thing occurred with the other school of 50 so that shortly there were four small schools of roughly 25 fish each.

The return cycle occurred when two of the non-feeding roving bands encountered each other and merged. During the period of observation there were many shifts of this sort, back and forth. When the observations were terminated, after about one hour, there was one group of about 75 and another of about 25. It is not to be supposed that this type of school dissolution and merging is especially common, but that it does happen gives some idea of the complexity of the basic pattern to be found in these fishes. More usually these features are so masked by various irrelevant details that only fragments of this action may be seen. There is, unfortunately, no way of distinguishing individuals, so it is not known what the minute-to-minute history of a single fish was in any instance. It would seem possible, however, that the fish that formed the feeding part were mostly those that had formed the non-feeding part in the prior situation.

\section{Vorticity in Other Systems}

The determination of various features of fish schools, especially as related to the water movements generated by the locomotor activities of the massed fishes, has naturally led to a variety of considerations borne upon by current thought in other fields of activity. The following comments indicate similarities and differences be- 
tween vortices found associated with fishes and found in other vortical situations.

In any study of animal assemblages it should be recognized that in the inanimate part of an environment a variety of physical forces causes non-locomotor, living or non-living, objects to assemble in groups, some even with a structure not unlike that of a fish school. In all assemblages there is evidently some part which is a mere submission to direct physical forces. In fact, one may consider part of animal activity to be as much a struggle to keep animals from being inertly accumulated in groups by these physical forces as it is a struggle to assemble in groups useful to the species. Reference to studies in other fields, not concerned with biological matters, underscores this condition: for instance, in cloud groups, Malkus (1963); in hurricanes, cyclones, galaxies and water masses, Rouse (1963); in physicists' order from disorder in particles, Purcell (1963); and in terms of general reference, as leaves caught up in a swirl of wind or water and iron filings in a magnetic field, Breder \& Halpern (1946). In all these as well as many others the assemblage has been sorted by the physical forces involved so that the items usually are nearly all of a single "species" with little jumbling of unlike things together.

Since fishes in a school are usually equipotential or nearly so, they are clearly redundant from the view of information theory and the larger the school the greater the redundancy. Schools vary greatly in size within a given species, some of the size differences being associated with the ecological and developmental condition of the participants and some associated with incidental details. Thus, the size of the schools of Mugil cephalus, for instance, increase greatly during the reproductive season while at other times the schools are usually much smaller but more numerous. As it is presumed that these assemblages have some utilitarian value, related to the life processes of the species concerned, the question of what determines an adequate redundancy, what is too much and what is too little, would seem to be of importance. This question can be discussed without immediate reference to the specific manner in which schools operate. It would seem that here is a situation that selection could easily alter. There is a variety of hypotheses and theories of the selective value concerning schooling versus non-schooling, as in Sette (1950), Atz (1953), Verheijen (1953 and 1956), Keenleyside (1955), Schäfer (1955), Brock \& Riffenburgh (1960), Brock (1962) and Olson (1964). These ideas, however valid some of them may be, are not in sufficiently specific form to be applied directly to present considerations.
If the equations of Johnson (1963), developed for a study of the relations of tissue redundancy to aging, be applied with suitable modification, to the size attainable and the length of time a fish school may exist, they would seem to have validity in terms of the present study. In this sense, a single schooling-type fish, $n=1$, should possess no redundancy and should be unstable. This certainly checks with the observed behavior of an isolated but normally schooling fish. Larger values for $n$ lead to greater redundancy and stability. This, in present terms, should mean that the larger the number of fishes in a school, the greater length of life for the school. Since curves of the family developed by Johnson loc. cit. can reach very large values of $n$, without substantially altering their basic nature, there would appear nothing in them to suggest a theoretical upper limit at which size a school would begin to lose integrity, unless limitations be set for the capacity of the environment or some unknown attribute intrinsic in a given species.

A consideration of the relationships within a fish school in reference to ideas centering about notions of "emergence" and whether a group is a mere aggregate of its parts or possessed of a "wholeness" of its own, leads to some interesting points. All such discussions are dogged by the inherent vagueness of many of the terms and concepts necessarily employed. Confining the study to fish groups brings in the possibility of being a little more precise in the handling of concepts which do not have to pretend to have universal application. A useful discussion of the semantics of notions about "wholes" and "parts," used in the broadest possible sense, is given by Nagel (1963).

Limiting the view to model groups in which all members are perfectly equipotential, the following conditions should obtain. In an equipotential model of a fish aggregation the only difference between it and a scattering of solitary individuals is that the fishes in the aggregation maintain themselves in a close association, without regard to orientation. The corresponding model of a fish school reduces the random nature of the fish orientations to one of regular order in which parallel swimming is the predominant feature. One of the results of this polarization is that the constituent fishes may be more closely packed and still retain adequate swimming room. By stipulation these two models of fish groups contain no other information than that given above and would seem to be at the very bottom of a series of organized animal groups, showing perhaps the first two steps which would have to be established as a basis for further structural complications. Although obviously many possibilities could exist, a conceivable next step could 
be the establishment of pod formation and still later, peck order.

In this one possible arrangement, there would be (a) mutual attraction to a standard distance, (b) polarization, (c) contact, (d) hierarchy. It is to be noted that these items are not all operating in the same direction. The addition of (b) to (a) tends to knit the group together. The addition of (c), the contact pod, to either (a) or (a) + (b) would seemingly make for an even more cohesive group, but the addition of (d) tends to disrupt either (a), (a) + (b), (a) + (c) or (a) $+($ b) + (c). It is to be noted that these four elements are features of the group and not the individuals comprising it, as obviously, for a single fish, (a), (b), (c) and (d) must always be zero. Thus these features can be considered as a new element not possessed by a solitary fish and to this extent, even in these simple associations, the whole is greater than the sum of its parts, something has "emerged"-a society of only very elemental features. These thoughts are clearly an oversimplification but such models should be useful in indicating the nature of what belongs to a fish and what to a fish group. Although many fish aggregations superficially appear to have nothing more than these models, it would seem probable that, on adequate analysis, other and subtle interindividual relations could be found. Also schools in which the members appear to be equipotential may in fact be merely ones in which the lack of such a state is masked because unequal potentials are balanced, a condition difficult to detect.

Since any aggregation of fishes may obviously be considered as a dynamic system of interacting parts, it is possible to treat the behavior of such a group in terms of the concept of stability. Analysis of this concept in other fields has frequently yielded valuable information covering the manner of operation of a great variety of diverse types of systems. See the review of Cunningham (1963). For present purposes it is sufficient to consider a stable system as one which, after small disturbances, returns to its former state, and an unstable one as a system in which small disturbances are not followed by a return to the former state but lead to a new one, which could include the final destruction of the system. Although such ideas go back at least to Liapunov (1892), stable and unstable systems are respectively systems with negative feedback and positive feedback, in the terminology of cyberneticists.

Systems, such as fish schools, cannot be linear, for if they were, the size of the disturbance would not be important, a situation that is certainly not true in any fish aggregation, where the magnitude of a disturbance has a distinct bearing on the outcome. This checks with theoretical considerations, as noted by Cunningham loc cit. The very fact that fish groups do occur demonstrates that they have some degree of stability which permits them to survive some kinds of minor disturbances and indicates the presence of negative feedback. This quantity may vary considerably and is often measured in a rough way by the terms "loose" and "tight," sometimes applied to fish schools or other groups such as aggregations, and pods. Here the coherence of the group increases from the first to the third as the fish pass from an aggregation to a school to a pod of individuals in physical contact.

The above approach to fish groups emphasizes the special nature of the fish school and bears on the meaning of some aspects of the descriptive equations, of Breder (1954 and 1959), which expressed the balance between the centrifugal and centripetal influences in the serried ranks of the fish school. What were called centripetal influences are clearly the effects of negative feedback, while those called centrifugal influences are the effects of positive feedback. It is obvious that the first must exceed the second at any distance between the fishes greater than the standard fish-to-fish distance for the group. At the established standard distance the positive feedback becomes precisely equal to the negative.

In terminology of ecologists the same thoughts may be attained by considering a fish school and its immediate environment as an ecosystem, which the term clearly covers. See, for instance, Egler (1964). Further elaboration at this point would be redundant.

\section{SUMMARY}

1. Since fishes produce vortices when swimming which surround them and leave a trail of dying vortices after them, it follows that these become a factor in the environment of those fishes accompanying them, an element that is of special significance to the structure of the fish school.

2. The side-to-side spacing of fishes in a school is usually just a little over twice the distance from the side of a fish to the outer edge of the trail of vortices in the area of their production, which insures their integrity until the fishes have left them behind.

3. As the maintenance of the integrity of these vortices is important to the efficiency of the fish's locomotor efforts, this may be the controlling factor that determines how closely fishes in a school approach each other.

4. There is usually continual shifting of positions of fish within a school which is evidently 
partly controlled by accidental encounters with parts of the vortices that reduce swimming efficiency. This continual adjustment by the fishes makes possible the continued existence of the group.

5. The range in sizes of fishes that may comprise a stable school appears to be limited to something closer than 1 to 0.6 , taking the largest individual as unity.

6. Also evidently responsible for some part of the continual shifting is the fact that the fish are not precisely of one size, nor are they of identical swimming ability or degree of fatigue, which produces somewhat of a conflict between individually preferred swimming speed and the attempt of each fish to keep close to its group.

7. Since vortices appear in various natural conditions from many sources, fishes make appropriate adjustments to them, especially noticeable in certain rates of flow where a stream may be filled with a mixture of several Kármán vortex trails, forcing fishes which venture into it to take a marked zigzag course, both avoiding adverse flow and benefiting from advantageous flow, from one sheltered place to another.

8. Closed figure fish schools, the so-called fish mills, may be initiated by both extrinsic and intrinsic causes, the first and classic cause being something that turns the forwardly placed members so they see the trailing members and proceed to follow them. The second is associated with the structure of the school involving viscous shear and showing behavior very like that of a viscid fluid.

9. The disruption of schools by violent means is usually followed by immediate re-formation, while disruption by specialized feeding methods or special feeding techniques is followed by reformation only after the full completion of the special action involved.

10. Considering the fish school as a system of interacting parts, the relations within it cannot be linear, for if they were, the reactions of a school as a whole would, on a basis of response to disturbances, be notably different.

11. Similarities and differences between the vorticular systems found in association with swimming fishes and the vortices found in other situations are discussed. Included are comments on the theoretical size limits of schools, the nature of their redundancy and the elements of attraction and repulsion present.

\section{BIBLIOGRAPHY}

ATz, J. W.

1953. Orientation in schooling fishes. In Proceedings of a Conference on Orientation in Animals, Feb. 6 and 7, 1953, Washington. Washington, D. C., Office of Naval Research, Department of the Navy, pp. 103-130.

BAINBRIDGE, R.

1958a. The speed of swimming fish as related to size and to the frequency of the tail beat. Jour. Exp. Biol., 35: 109-133.

1958b. The locomotion of fish. New Scientist, 4: 476-478.

Bainbridge, R., \& R. H. J. Brown

1958. An apparatus for the study of the locomotion of fish. Jour. Exp. Biol., 35: 134137.

BergeiJK, H. A. VAN

1964. Evolution of binaural hearing. [Abstract A9.] Program of the 67 th meeting of the Acoustical Society of America: 8 .

BIRKHOFF, G.

1962. Helmholtz and Taylor instability. Proc. Symposium Applied Math., Amer. Math. Soc.. 13: 25-33.
BREDER, C. M., JR.

1924. Respiration as a factor in locomotion of fishes. Amer. Nat., 58: 145-155.

1925. Fishes squirting water. Bull. New York Zool. Soc., 28 (3) : 69-72.

1926. The locomotion of fishes. Zoologica, 4: 159-297.

1951. Studies on the structure of the fish school. Bull. Amer. Mus. Nat. Hist., 98: 1-28.

1954. Equations descriptive of fish schools and other animal aggregations. Ecology, 35 (3) : 361-370.

1959. Studies on social groupings in fishes. Bull. Amer. Mus. Nat. Hist., 117: 393-482.

Breder, C. M., Jr., \& F. Halpern

1946. Innate and acquired behavior affecting aggregations of fishes. Physiol. Zool., 19: 154-190.

Brock, V. E.

1962. On the nature of the selective fishing action of longline gear. Pacific Science, 16 (1): $3-14$

Brock, V. E., \& R. H. RifFENBURGH

1960. Fish schooling: a possible factor in reducing predation. Jour. du Conseil, 25 (3): 307-317. 


\section{Cahn, P., \& E. Shaw}

1963. Schooling fishes: the role of sensory factors. Animal Behaviour, 11: 2-3. [Abstract.]

[MS.]. A method for studying lateral line cupular activity of juvenile fishes.

\section{Cunningham, W. J.}

1963. The concept of stability. Amer. Scientist, 51 (4): 425-436.

EgLeR, F. E.

1964. Pesticides-in our ecosystem. Amer. Scientist, 52 (1): 110-136.

FRY, F. E. J., \& J. S. HART

1947. Cruising speed of goldfish in relation to water temperature. Jour. Fish. Res. Board Canada, 7 (4): 169-175.

GADD, G. E.

1963a. Some hydrodynamical aspects of swimming. Ship Rept. 45, Natl. Phys. Lab., Ship Div., Feltham, England: 1-26.

$1963 \mathrm{~b}$. The hydrodynamics of swimming. New Scientist, 19 (355): 483-485.

Hill, A. V.

1949. The dimensions of animals and their muscular dynamics. Royal Institution of Great Britain, Weekly Evening Meeting, Nov. 4: 1-24.

JoHN, K. R.

1964. Illumination, vision and schooling of Astyanax mexicanus (Fillipi). Jour. Fish. Res. Bd. Canada, 21 (6): 1453-1473.

Johnson, H. A.

1963. Redundancy and biological aging. Science, Sept. 6, 141: 910-912.

KÁRMÁN, T. voN

1912. Über den Mechanismus des Widerstandes den ein bewegter Körper in einer Flüssigkeit erfährt. Nachr. d. Wiss. Ges. Göttingen, Math. Phys. K1., 509 (1911) and 547 (1912).

Keenleyside, M. H. A.

1955. Some aspects of the schooling behaviour of fish. Behaviour, 8 (2-3): 183-248.

Liapunov, M. A.

1892. In Russian. Karkov. Problème général de la stabilité du mouvement. Annales de Toulouse, 9 (2): 203-474, 1907. Princeton University Press 1949, Ann. Math. Study No. 17.

Malkus, J. S.

1963. Cloud patterns over tropical oceans. Science, Aug. 30, 141: 767-778.

\section{MATSCHINSKI, M.}

1953. La mécanique de la nage chez les poissons. Bull. Français Piscicult., no. 171: 45-73.
MIYADI, D.

1958. Perspectives of experimental research on social interference among fishes. In Buzzati-Traverso, A. A. (ed.), Perspectives in marine biology. Berkeley, University of California Press: 469-479.

Moulton, J. M.

1958. The acoustical behavior of some fishes in the Bimini area. Biol. Bull., 114 (3): 357 374.

NAGEL, E.

1963. Wholes, sums and organic unities. In Lerner, D. (ed.), Parts and wholes. Glencoe, New York, The Free Press: 135-155.

OHshima, Y.

1950. An experiment on the shoaling behaviour in fish: The case when two homotypic shoals consisting of large and small individuals met with each other. Bull. Japanese Soc. Sci. Fish., 16 (5) : 195-200.

OKuno, R.

1962. Distribution of young of two reef fishes, Girella punctata Gray and G. melanichthys (Richardson), in Tanabe Bay and the relationship found between their schooling behaviors. Publs. Seto Marine Biol. Lab., Kobe, Japan, 10 (2) : 293-306.

1963. Observations and discussions on the social behaviors of marine fishes. Ibid., 11 (2) : 281-336.

Olson, F. C. W.

1964. The survival value of fish schooling. Jour. du Conseil, 29 (1): 115-116.

PARr, A. E

1927. A contribution to the theoretical analysis of the schooling behavior of fishes. Occas. Papers Bingham Oceanogr. Coll., no. 1: 1-32.

PRANDTL, L.

1904. Über Flüssigkeitsbewegung bei sehr kleiner Reibung. Verhandlungen des III Internat. Math.-Kongresses, Heidelberg: 484-491.

Purcell, E.

1963. Parts and wholes in physics. In Lerner, D. (ed.), Parts and wholes. Glencoe, New York, The Free Press: 11-39.

Rosen, M. W.

1959. Water flow about a swimming fish. Station Tech. Publ. U. S. Naval Ordnance Test Station, China Lake, California, NOTS TP 2298: i-v, 1-94.

Rouse, $\mathrm{H}$.

1946. Elementary mechanics of fluids. New York, John Wiley \& Sons, Inc.: i-xii, 1376. 
1963. On the role of eddies in fluid motion. Amer. Scientist, 51 (3): 285-314.

SCHAEFER, M. B.

1948. Size composition of catches of yellowfin tuna (Neothunnus macropterus) from Central America and their significance in the determination of growth, age and schooling habits. Fish. Bull. Fish \& Wildlife Serv., 51 (44): 197-200.

SCHÄFER, W.

1955. Über das Verhalten von Jungerheringsschwarmen im Aquarium. Arch. f. Fischereiwiss., yr. $6(5 / 6): 276-278$.

\section{SCHLICHTING, H.}

1951. Boundary layer theory. Fourth ed. English. Dr. J. Kestin translator. 1960, New York, McGraw-Hill Book Co., i-xx, 1647.

Sette, O.

1950. Biology of the Atlantic mackerel (Scomber scombrus) of North America. Part II. Migrations and habits. Fish. Bull. Fish \& Wildlife Serv., 51 (49): 251-358.

SHaw, E.

1958a. A study of current orientation as a stimulus to schooling behavior in Menidia. [Abstract.] Biol. Bull., 113 (2) : 354-355.

1958 b. A study of visual attraction as a stimulus to schooling behavior in Menidia. [Abstract.] Ibid., 115 (2): 365.

1961. Minimal light intensity and the dispersal of schooling fish. Bull. Inst. Oceanogr. Monaco, no. 1213: 1-8.

Shaw, E., \& A. Tucker

[In Press]. The optomotor response of schooling carangid fishes. Animal Behaviour.

Shaw, W. C.

1959. Sea animals and torpedoes. Navord Rept. 6573, Tech. Publ. U.S. Naval Ordnance Test Station, China Lake, California, NOTS TP 2299: i-vii, 1-44.

SHULEIKIN, V. V.

1958. How the pilot fish moves with the speed of the shark. Doklady Akad. Nauk S.S.S.R. Transl. Biol. Sci. Sect., 119 $(1 / 6): 140-143$.

Townsend, C. H.

1909. Water-throwing habit of fishes in the New York Aquarium. Bull. New York Zool. Soc., no. 33: 488.

VERHEIJEN, F. J.

1953. Laboratory experiments with the herring, Clupea harengus. Experientia, 9, fasc. 5: 193-194.

1956. Transmission of a flight reaction amongst a school of fish and the underlying sensory mechanism. Ibid., 12, fasc. 5: 202 204.

WALTERS, V.

1962. Body form and swimming performance in the scombroid fishes. Amer. Zool., 2 (2) : 143-149.

\section{EXPLANATION OF THE PLATES}

Plate I. Goldfish in a suspension of bentonite, showing flow lines. Courtesy of the Goodyear Aircraft Corp.

Plate II. A school of Thunnus thynnus viewed from the air. Courtesy of Mr. George A. Bass.

Plate III. Upper: An “exploding” school of Mugil cephalus, startled by a passing kingfisher. Lower: A tight school of Mugil cephalus under which condition there is little forward translation, except at the upper margin, which shows loosening with increased forward movement.

Plate IV. Stages in mill formation within a school of Mugil cephalus, showing the "viscous shear" type of origin. The position of the school in the successive stages is indicated by the wisp of grass on the shore showing in the lower right-hand margin. The two time intervals between the three photographs are about equal, at approximately eight seconds. 

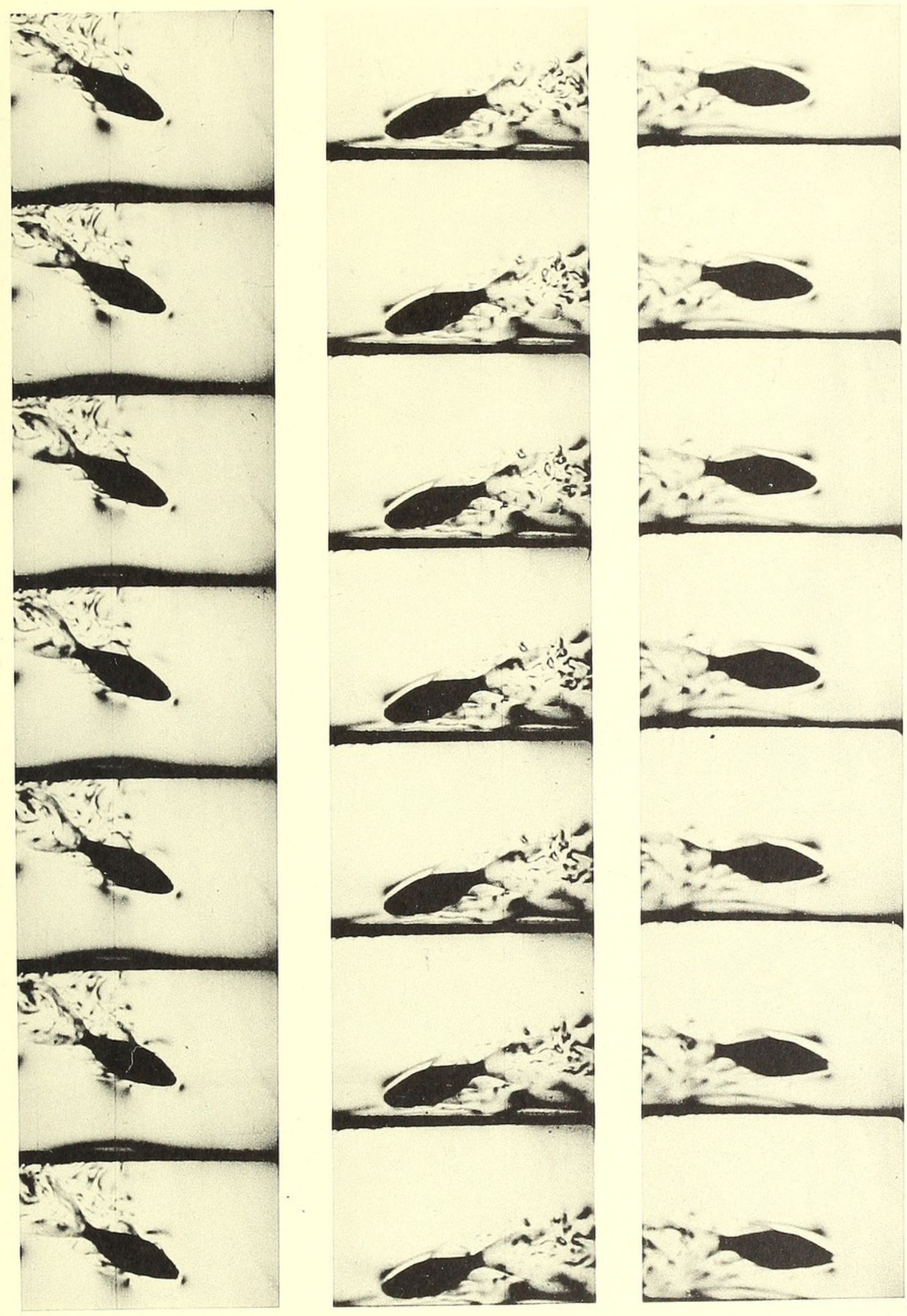

VORTICES AND FISH SCHOOLS 


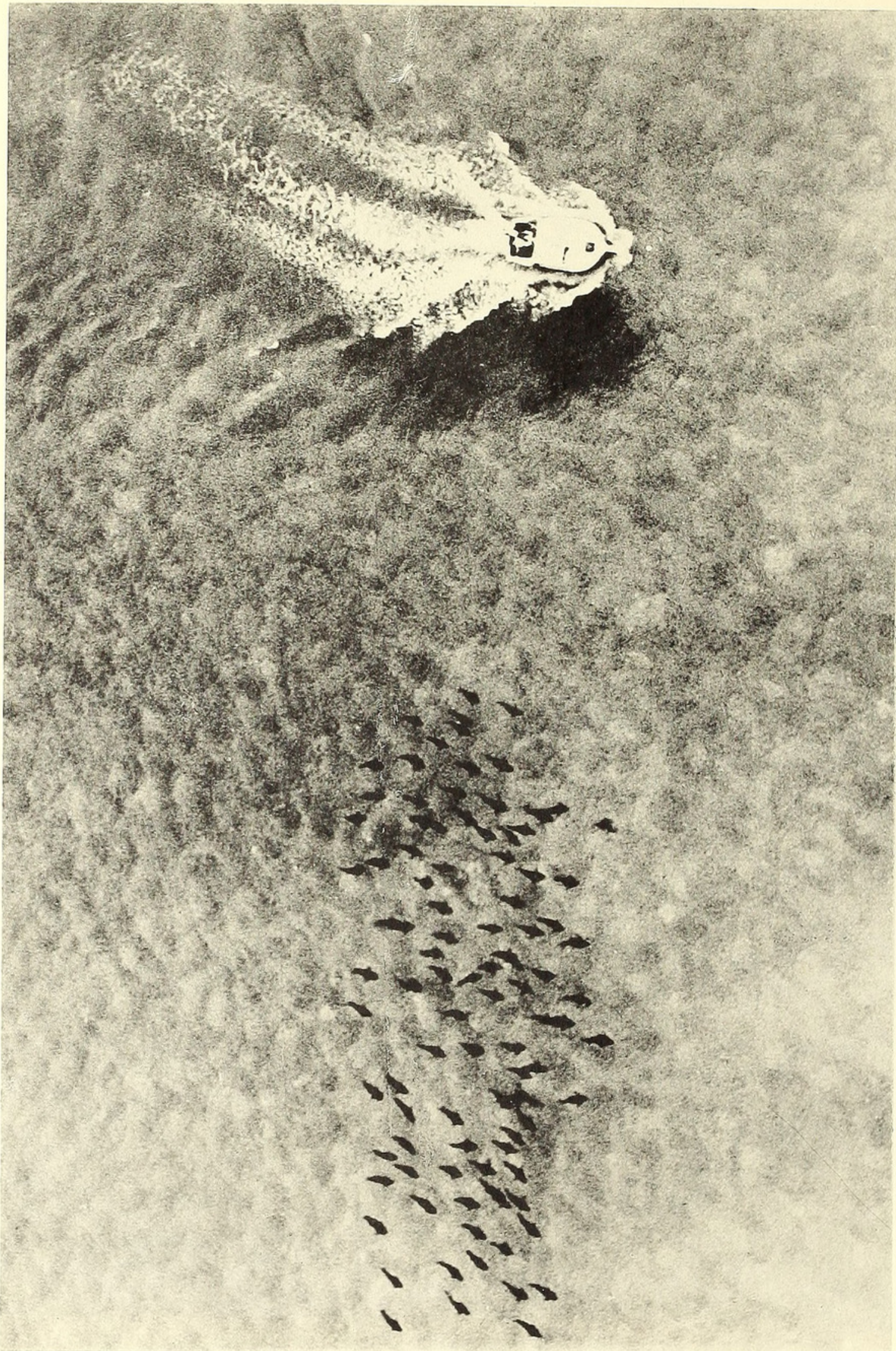



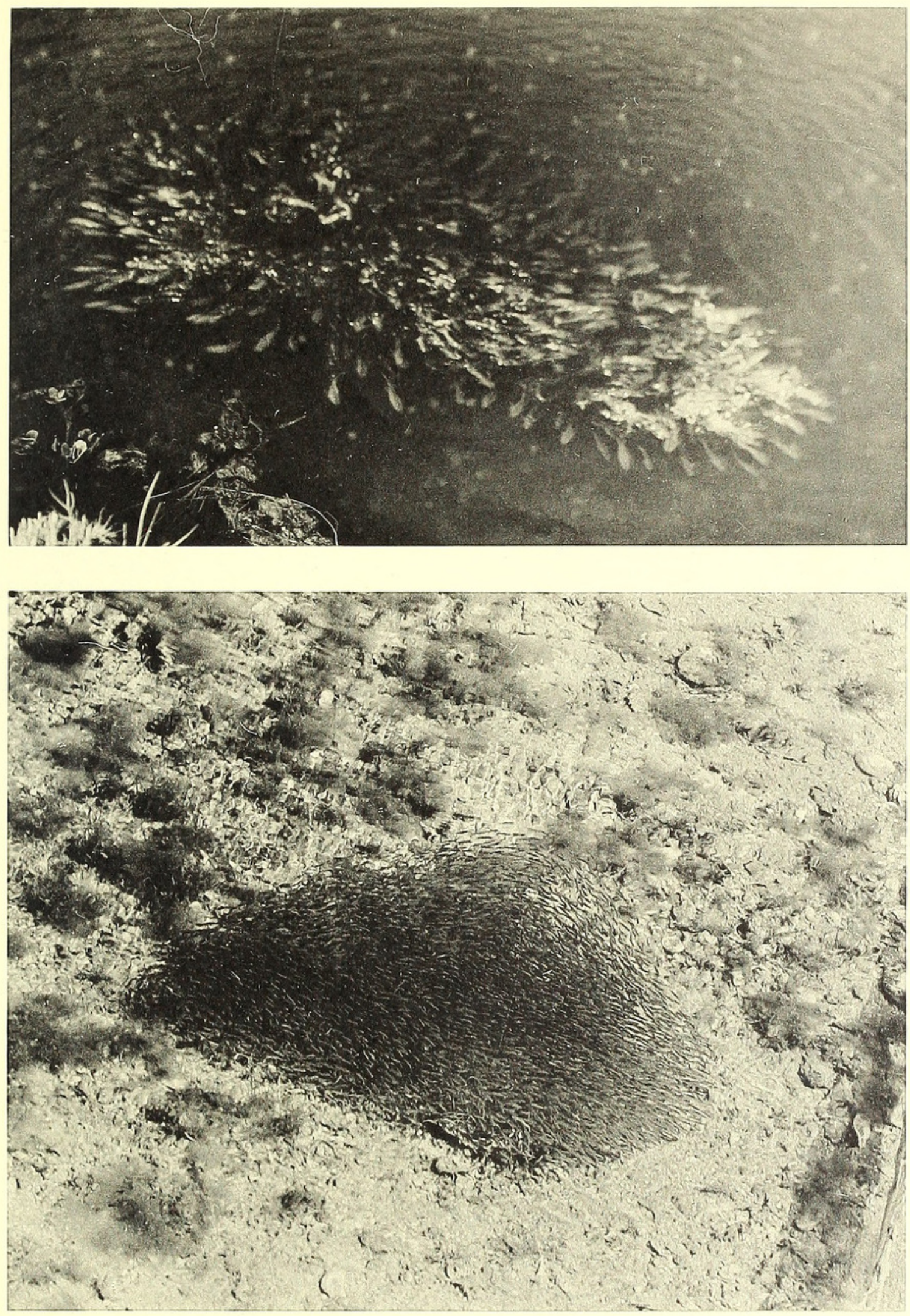

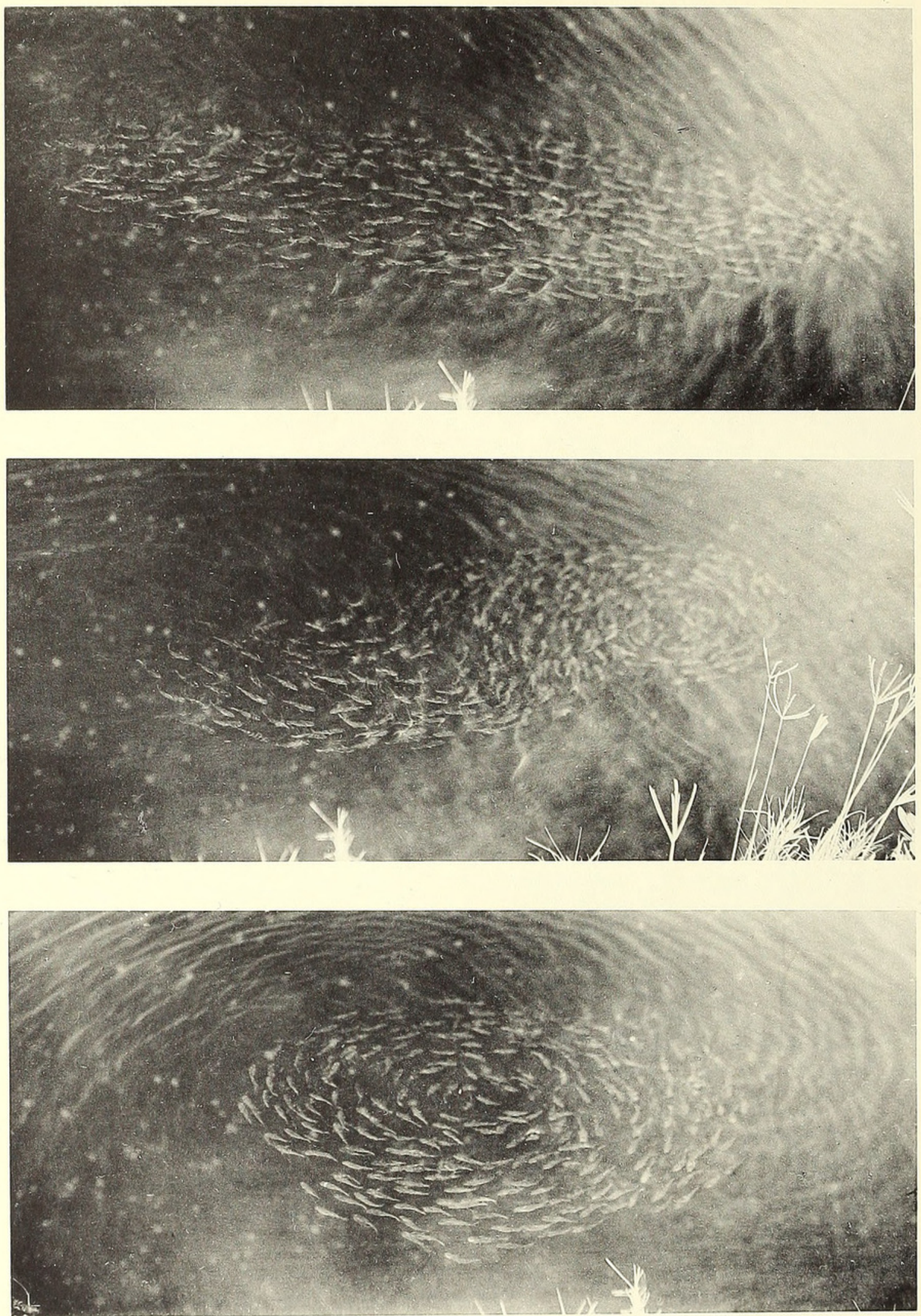

VORTICES AND FISH SCHOOLS 


\section{$2 \mathrm{BHL}$ Biodiversity Heritage Library}

Breder, Charles M. 1965. "Vortices and fish schools." Zoologica : scientific contributions of the New York Zoological Society 50(10), 97-114. https://doi.org/10.5962/p.206663.

View This Item Online: https://www.biodiversitylibrary.org/item/208152

DOI: https://doi.org/10.5962/p.206663

Permalink: https://www.biodiversitylibrary.org/partpdf/206663

\section{Holding Institution}

Smithsonian Libraries

\section{Sponsored by}

Biodiversity Heritage Library

\section{Copyright \& Reuse}

Copyright Status: In Copyright. Digitized with the permission of the rights holder

Rights Holder: Wildlife Conservation Society

License: http://creativecommons.org/licenses/by-nc/3.0/

Rights: https://www.biodiversitylibrary.org/permissions/

This document was created from content at the Biodiversity Heritage Library, the world's largest open access digital library for biodiversity literature and archives. Visit BHL at https://www.biodiversitylibrary.org. 